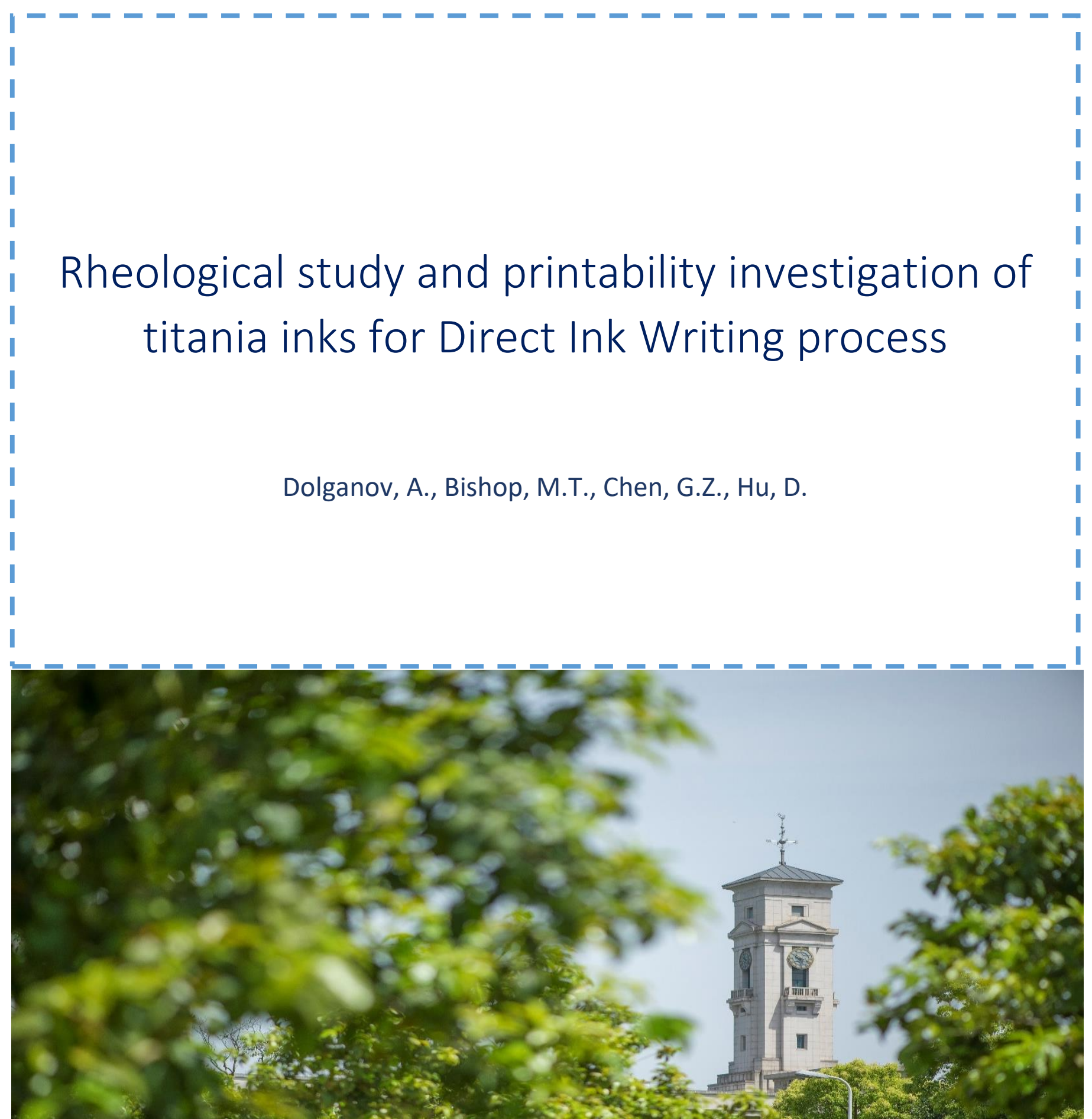

titania inks for Direct Ink Writing process

Dolganov, A., Bishop, M.T., Chen, G.Z., Hu, D. 
University of Nottingham Ningbo China, 199 Taikang East Road, Ningbo, 315100, Zhejiang, China.

First published 2021

This work is made available under the terms of the Creative Commons Attribution 4.0 International License:

http://creativecommons.org/licenses/by/4.0

The work is licenced to the University of Nottingham Ningbo China under the Global University Publication Licence:

https://www.nottingham.edu.cn/en/library/documents/researchsupport/global-university-publications-licence-2.0.pdf 


\section{Rheological Study and Printability Investigation of Titania Inks for Direct Ink Writing Process}

Aleksei Dolganov ${ }^{\mathrm{a}}$, Matthew T. Bishop ${ }^{\mathrm{a}, \mathrm{b}}$, George Z. Chen ${ }^{\mathrm{a}, \mathrm{b}, \mathrm{c}}$, Di Hu ${ }^{\mathrm{a}, \mathrm{b}, \mathrm{d}, *}$

a. Department of Chemical and Environmental Engineering, The University of Nottingham Ningbo China, 315100, PR China.

b. International Doctoral Innovation Centre, The University of Nottingham Ningbo China, Ningbo, 315100, PR China.

c. Department of Chemical and Environmental Engineering, Advanced Materials Research Group, Faculty of Engineering, The University of Nottingham, Nottingham NG7 2RD, UK.

d. Advanced Energy and Environmental Materials \& Technologies Research Group, The University of Nottingham Ningbo China, Ningbo, 315100, PR China.

* Corresponding author: di.hu@ nottingham.edu.cn

Keywords: Rheology, Titanium Dioxide, Titania, Direct Ink Writing

\section{Abstract}

Titanium dioxide is widely used in numerous industries and with the newly developed titanium manufacturing technic, referred to as the Near-net-shape Electrochemical Metallisation (NEM) Process, the rapid and precise production of titanium dioxide components is highly sought-after. This manuscript presents the rheological investigation and extrudability tests of titania inks, to 
establish the improved production of titanium dioxide components via Direct Ink Writing. The extrudability tests indicated that despite an unfavourable increase in viscosity during the high shear rates (dilatancy peaks), the best-performing ink had a weight ratio of 1:0.8:0.1 $\mathrm{TiO}_{2}: \mathrm{H}_{2} \mathrm{O}: \mathrm{PEG}$, and the dilatancy peaks were smoothed out with the addition of 0.1 weight ratio of oleic acid to the ink, dramatically improving the quality of the product. To further improve the green bodies a new printing approach was also introduced, removing the necessity for specialised printing bed, by printing a removable support into the green body and allowing for drying without any cracks and warping. 


\section{Introduction}

For the past 40 years the concept of Additive Manufacture (AM), such as 3D printing, has developed into several different techniques that allow AM to work with numerous different materials such as food, polymers, ceramics, and metals [1-3]. Among those, the AM of metals and ceramic materials has been thoroughly investigated, due to the engineering importance of these materials within multiple industries $[4,5]$. While metals can conventionally be produced in almost any desired shape using various AM techniques, conventional ceramic manufacturing is more complex due to their higher melting temperatures, hardness and lower ductility, making the AM of ceramics highly sought-after.

Nowadays, AM of ceramic consists of such techniques including Direct Ink Writing (DIW) [6-9], Selective Laser Gasifying (SLG) [10], Selective Laser Sintering (SLS) [11], stereolithography (SLA) [12, 13], Layer-wise Slurry Deposition (LSD) [14], Binder Jetting (BJ) [15], and replication [16]. All of these techniques have been shown to be suitable for the production of solid ceramic parts, however, DIW is widely considered as the simplest and most affordable ceramic AM technique [6-9].

Among the wide range of ceramic materials, titanium dioxide (i.e., titania) has a great potential for its biocompatibility, hardness, stiffness and heat resistance [17, 18], implying almost limitless applications in industries related to food, biomedical, etc. The recent developments in DIW of titanium dioxide have focused on the production of scaffolds or biomedical implants and the manufacture of dense ceramic components $[19,20]$. It is important to highlight that such scaffolds are required to possess a certain porosity to allow for body tissue to grow through it, resulting in improved biocompatibility $[17,21]$. In addition, mechanical properties of such scaffolds are 
required to be close to that of a human bone, to reduce stress shielding and minimise bone resorption [20]. The properties such as stiffness and compressive strength can be achieved by manipulating the structure or porosity of the bulk material.

Another potential application of DIW of titanium dioxide is the recently proposed manufacturing of titanium components via the Near-net-shape Electrochemical Metallisation (NEM) Process [21]. This is an indirect titanium AM process where the ceramic green body (i.e., metal oxide or its mixtures) is 3D printed first and then in situ metallised to its metal or alloy counterpart via the solid-state deoxidation process in a molten salt (i.e. the FFC-Cambridge Process), with a shape and structure close to that of the original ceramic green body: a unique feature of the FFCCambridge Process for metal extraction [22, 23].

The difference in the requirements for the feedstock for the NEM Process, compared to the solid ceramic production, leads to a specifically tailored morphology and purity of the printed precursor. Firstly, the ceramic body has to possess a porosity greater than $12 \%$ as this is one of the key driving factors for the successful and complete deoxidation (i.e., metallisation) of the ceramic precursor [24-26]. Secondly, the produced ceramic precursor has to be free of the impurities like sulphur, nitrogen and especially unwanted metal oxide/compounds. Such a requirement is formulated due to the inherent nature of the metallisation process where metal is formed. During this stage, any unwanted metal oxide/compound can be metallised as metal impurities on or within the product, affecting the purity of the final product. Elements like nitrogen, sulphur, etc. affect the properties of the electrolytically produced metal or alloy, and when applied to titanium and its alloys, they can produce undesired reactions and lower the quality of the product [27]. Therefore, due to these restrictions, there is a demand for the investigation of an alternative ink formulation for the DIW process. 
This manuscript presents the investigation into the rheological modifiers of original titania inks needed to ensure a stable and consistent printing process, which will ensure the highest precision DIW applied for engineering and bioengineering fields. Additionally, due to the above-discussed potential negative effects of the residue materials and to provide a cleaner material for the biomedical applications, the selection of the organic additives within the titania inks is limited to those containing only hydrogen, carbon and oxygen. Overall, this study aims to improve the understanding of the physical flow behaviour of complex inks of titania and propose simpler, cheaper and safer processing.

\section{Experimental}

\subsection{Feedstock}

To produce the titania inks, titanium dioxide $\left(99.5 \% \mathrm{TiO}_{2}\right.$, Aladdin, $60 \mathrm{~nm}$, rutile, Figure 1) was mixed with deionised water or a solution of selected additives with a mortar and pestle for 10 minutes. Two rheological modifiers, polyethylene glycol (PEG) (SCR, Average molecular weight: 6000) and polyvinyl alcohol (PVA) (Aladdin, 87-89 mol\%, 3.2-3.6 mPa.s), were applied in this study for investigating their binding and dispersive properties, as well as the optimised weight ratio of rheological modifiers to titanium dioxide. These rheological modifiers were selected due to being commonly applied in the DIW [6]. PEG was dissolved in water at room temperature, while PVA required heating of $60{ }^{\circ} \mathrm{C}$ in order to be fully dissolved. Typically, temperatures exceeding $90{ }^{\circ} \mathrm{C}$ is used to dissolve PVA, however, the PVA used in this investigation was fully hydrolysed and, therefore, the dissolution temperature can be as low as $60{ }^{\circ} \mathrm{C}$ [28]. These mixtures were then mixed with titanium dioxide to follow a specific weight ratio, which is indicated in the 
names of samples as $\mathrm{X}: \mathrm{Y}: \mathrm{Z}$ (for example 1:0.8:0.1 PEG), where $\mathrm{X}$ is the ratio of $\mathrm{TiO}_{2}$, $\mathrm{Y}$ the ratio of water and $\mathrm{Z}$ the ratio of PEG or PVA. The produced inks were then subjected to a series of rheological and printable tests for DIW.

The samples were divided into 3 groups based on their water content (i.e. 1; 0.9 and 0.8 ). These intervals were selected due to the extreme sensitivity of the inks, which prevented the accurate preparation of fractional samples (e.g. 0.95 and 0.85). Additionally, samples above 1 and below 0.8 were found to be too fluid $(>1)$ and too solid in nature $(<0.8)$ for effective extrusion and testing.

\subsection{Rheological tests}

Rheological tests were conducted on Kinexus rheometer KNX2100 (Malvern Panalytical Ltd) using $20 \mathrm{~mm}$ stainless steel disc and a gap of $1 \mathrm{~mm}$. All experiments were conducted at $25{ }^{\circ} \mathrm{C}$. Two types of test were performed:

- Rotational

○ The test was performed for a shear sweep of 100 to $0.01 \mathrm{~s}^{-1}$.

- Creep and relaxation

$\circ$ The test was performed to end at a time of 5 seconds for both creep and relaxation parts with the applied shear stress of $1 \mathrm{~Pa}$.

\subsection{Extrudability}

For this work, extrudability is defined as an ability to be extruded through a selected nozzle size of $0.5 \mathrm{~mm}$. This means that the result can be described according to the following criteria:

1. Unextrudable - Cannot be extruded.

2. Uncontrollably extrudable. - The ink possesses high fluidity and cannot retain its shape. 
3. Extrudable with occasional inconsistencies. - The ink possesses inconsistency in the flow.

4. Controllably extrudable. - The ink can be extruded without any deviations in the flow.

Extrudability tests were conducted in two phases. Firstly, a rivet with $10 \times 10 \times 10 \mathrm{~mm}(\mathrm{~L} \times \mathrm{W} \times$ H) dimensions was printed. Based on the results of the first phase, the second phase focused on the production of an impeller with the dimensions of $40 \times 40 \times 18 \mathrm{~mm}(\mathrm{~L} \times \mathrm{W} \times \mathrm{H})$. This is done in order to test the material for the production of larger objects and eliminate criteria 1 and 2.

The whole process took place on a modified Fused Deposition Modelling (FDM) 3D printer (LUOBO, China) connected with a conventional air compressor with a working pressure range of 0.1-0.6 MPa and a maximum output of $0.8 \mathrm{MPa}$.

\section{Results and discussion}

\subsection{Rheological evaluation.}

An evaluation of the relationship between shear rate and shear viscosity showed the shear thinning behaviour across all the inks. Figure 2 indicates that with increasing shear rate, shear viscosity reduces, which is an indicator of a shear-thinning response and pseudo-plastic behaviour.

Inks without any additives showed highly unstable behaviour that affected rheological readings, as they did not follow any trend compared to other samples (see Figure 2 A). It was not possible to achieve a stable suspension of titanium dioxide without additives for samples 1:1 $\mathrm{H}_{2} \mathrm{O}$ and 1:0.9 $\mathrm{H}_{2} \mathrm{O}$, leading to the appearance of random peaks, which implies signs of agglomeration and relatively higher loading across the samples (as seen in Figure 2 A). 
The addition of PEG to an ink resulted in a shear thickening region in the range of 2 to $7 \mathrm{~s}^{-1}$ (as shown by the increase in shear viscosity in Figure $\mathbf{2}$ B) and was previously observed and discussed by Ge, et al. [29]. Such a phenomenon is caused by the interaction of spherical particles suspended in solutions containing polymers with relatively long polymer chains [30], resulting in the agglomeration of particles at a particular shear rate. As the agglomeration of particles increases, an inevitable risk of clogging occurs in the nozzle of the DIW 3D printer.

Samples containing PVA presented an apparent reduction in viscosity, shown by a plateau at higher shear rates, making them behave as a viscous slurry (see Figure 2 C). Therefore, produced graphs in Figure $2 \mathbf{C}$ can be divided into two parts: shear thinning (at 0.01 to $2 \mathrm{~s}^{-1}$ ) and a slight shear-thickening region (at 2 to $100 \mathrm{~s}^{-1}$ ). This second part can occur as a result of a reformed morphology of the ink, due to the binding properties of PVA. At higher loads of $\mathrm{TiO}_{2}$ particles, the ink was showing obvious shear thickening behaviour, which could not be tested on the rheometer due to the ink being tightly packed.

To investigate the viscoelastic properties of the inks, creep and recovery tests were conducted, as shown in Figure 3.

Overall, Figure 3 displays a viscoelastic behaviour with dominant viscous characteristics across all samples, which is represented by a relatively small reduction of strain after about 5 seconds (recovery phase). Additionally, samples with a lower content of titanium dioxide followed trends of increased strain (as seen from the Y-axis in Figure 3). Therefore, this results in the ability of inks, with a higher weight ratio of titanium dioxide, to withstand higher loads when applied to DIW, meaning that the extrusion pressure will be higher and the produced object will be sturdier. 
As noted previously, water-based inks showed unstable results with elastic reformation fluctuating between $10 \%$ and $80 \%$. Additionally, the resulted magnitude is not representative with respect to the individual loading of the tested inks (see Figure $3 \mathbf{A}$ ). It is important to note that PEG samples in Figure 3 B show almost viscous behaviour with negligible elasticity, as demonstrated by the lack of the elastic reaction after the creep phase has ended. This behaviour is linked to the surfactant effect of PEG. It allows the ink to flow better and reduce the viscoelastic component of an ink. However, DIW inks are expected to be viscoelastic in nature and therefore suggests that PEG may possess unsuitable properties. Figure $3 \mathbf{C}$ shows that, on average, PVA based inks had a $30 \%$ reformation ability, which means that the ink tends to retain $30 \%$ of its initial structure. While utilising such inks in extrusion can be beneficial for shape conservation, the extrusion process could theoretically become constrained due to the additional resistance stored in the ink.

Testing shear stress (Figure 4) showed that most of the inks followed a shear-thinning trend that is represented by a stabilisation of the shear stress value, however, this observation is obscured by the elastic reaction at the beginning of curves in Figure $4 \mathbf{A}$ and $\mathbf{B}$. This reaction is represented in initial spikes of shear stress, which can be associated with the stable structure that forms during the idle state. This structure creates a resistance to flow and, therefore, increased shear stress. When repeating the tests all peaks persist, meaning that the formation time of the resistant structure is extremely short. Furthermore, Figure 4 B shows that samples with PEG show fluctuation before the logarithmic increase. This fluctuation has appeared in the dilatancy peak range ( 2 to $7 \mathrm{~s}^{-1}$ ), observed in shear viscosity versus shear rate tests (see Figure 2 B). These dilatancy peaks represent the increase in viscosity during the high shear rates, which is associated with an inconsistency when printing larger scale products. Overall, this means that when applied to DIW, the inks will become stable soon after they are extruded. Samples with PVA once again showed almost ideal 
viscous behaviour, which means that these samples will most likely not be able to be implemented into the DIW process due to their fluid nature and thus uncontrollable extrusion (see Figure 4 C). It is important to note that PVA samples were very sensitive to the loading of titanium dioxide, with small increases transforming low viscosity ink into a thick shear thickening paste. These thick pastes were not suitable for extrusion and rheometry and thus were not investigated.

\subsection{Extrudability.}

When using the variations of inks discussed above as inks for DIW printing, only 1:0.8:0.1 and 1:0.9:0.1 PEG were able to be extruded without any clogging through a $0.5 \mathrm{~mm}$ nozzle. Table 1 contains a summarised extrudability evaluation with images where it was appropriate.

PVA based inks were determined to be uncontrollably extrudable, failing to maintain any shape and most of the water-based samples were not extrudable at any composition. As seen from Table 1 only samples with weight ratios of 1:0.8:0.1 and 1:0.9:0.1 $\mathrm{TiO}_{2}: \mathrm{H}_{2} \mathrm{O}: \mathrm{PEG}$ produced relatively good results. The formula of 1:1:0.1 $\mathrm{TiO}_{2}: \mathrm{H}_{2} \mathrm{O}: \mathrm{PEG}$, however, could not be printed consistently due to blockages that resulted in a sudden and uncontrollable extrusion. It is important to note that increasing the nozzle size to $1 \mathrm{~mm}$ allowed every ink to be extruded, however, this limits the resolution of the product.

As a result of rheological and extrusion tests, it was established that titania inks could not be reliably printed without the addition of rheological modifiers. It was also found that commonly used PVA had a negative effect on the ink, transforming it from a liquid to a thick paste. This means that among the investigated material only PEG satisfied the established requirements by producing green bodies that contained only $\mathrm{TiO}_{2}$, carbon, and hydrogen. The application of this 
paste also satisfied the requirements of high porosity for the NEM Process, which was measured to be up to $71 \%$.

\subsection{Further optimisation.}

By combining the findings from rheological tests and the extrudability evaluation (Figures 1-3 and Table 1, respectively), PEG-based inks with the ratio of 1:0.8:0.1 $\mathrm{TiO}_{2}: \mathrm{H}_{2} \mathrm{O}: \mathrm{PEG}$ were proven to have the most suitable rheological parameters (i.e., shear thinning and almost viscous) for the DIW. However, the shear thickening region for the PEG-based inks was shown to result in an inconsistent flow, especially as the printing size was scaled up. Moving from $10 \mathrm{~mm}$ wide shape to $40 \mathrm{~mm}$ resulted in the observed inconsistency of the flow of the ink, similar to that of 1:1:0.1 $\mathrm{TiO}_{2}: \mathrm{H}_{2} \mathrm{O}: \mathrm{PEG}$ sample (see Figure $6 \mathrm{~A}$ ). By applying a surface lubricant in the ratio of $1 \mathrm{TiO}_{2}$ to 0.1 oleic acid (SCR, CP) (i.e., 1:0.8:0.1:0.1 $\mathrm{TiO}_{2}: \mathrm{H}_{2} \mathrm{O}: \mathrm{PEG}$ :oleic acid) the flow became more stable, meaning that particles were not constrained by PEG polymer chains at higher shear rates, due to reduced friction between the components of the ink. This was confirmed by a rheological investigation, showing that the dilatancy peak, at the range of 2 to $7 \mathrm{~s}^{-1}$, was reduced (see Figure 5). Figure 5 also indicates the appearance of a plateau at the low shear rates, which beneficially affects the extrusion process as the flow in that region will be constant. The benefits of the updated formula were highlighted in the production of the complex shape of an impeller, which resulted in better surface finishing and a higher precision of the final dimensions with the incorporation of oleic acid, as seen from Figure 6.

\subsection{Effects of additives}

From the produced investigation, it was found that the ink containing $1 \mathrm{TiO}_{2}, 0.8 \mathrm{H}_{2} \mathrm{O}$ and 0.1 PEG (weight ratios) produced the best result for the DIW process. As stated previously, the inks with PEG and titanium dioxide were more stable compared to the plain mix of water and titanium 
dioxide. This is due to the hydrophilic properties of the polymer, coordinating with water, which causes the long polymeric chains of PEG to become entangled among the solid particles of titanium dioxide, creating a stable system without separation of the liquid (see Figure $7 \mathbf{A}$ and $\mathbf{B}$ ). The proposed system structure also matches the one described in the jamming theory that was applied to a PEG-based system mentioned earlier.

SEM images of the samples demonstrate that PEG had a medium binder effect on the structural integrity, as shown by the segmented nature of the green body in Figure $\mathbf{7 ~ C}$ and the integrated structure in Figure 7 D. This makes the product less brittle and produce less of the residue powder when handled. It is also visible that particles are linked with solidified PEG after its application (Figure 7 D). This finding removes the necessity for an additional binder that is typically required for a green body to maintain its shape [31].

Moreover, such entrapment of water reduces the migration of water molecules from the ink during the DIW process as illustrated in Figure 8. This conclusion was made due to the increased viscosity of the ink before and after the DIW process, which resulted in the requirement to increase the extrusion pressure as the DIW process continued [32]. This migration was reduced by the addition of rheological modifiers and using nozzles not smaller than $0.5 \mathrm{~mm}$.

\subsection{Drying behaviour}

Drying of ceramic green bodies was thoroughly studied due to the high impact it induces on the final shape of a product [33]. Generally, drying is interconnected with shrinkage that occurs when a solvent is removed from the ceramic bulk. When drying is uneven, the shape, due to the uneven shrinkage, typically undergoes deformation more widely known as warping [34]. In addition to warping, a ceramic green body that is drying on a surface with high attachment/stickiness often results in cracks, due to the high traction between some areas of the product, especially affecting 
flat shapes such as slabs [35]. Typically, uneven drying is removed via slow drying rates, which, however, does not provide a solution to cracks [34].

During this study, it was noted that, upon drying, samples tended to shrink, losing $10 \%$ of the original dimensions. This happened uniformly in all directions and caused samples to crack if printed directly on the printing bed. To mitigate the cracking every sample was printed on a $3 \mathrm{~mm}$ tall titania grid, which functioned as a support. This technique not only removed the necessity for additional treatment of the printing bed [36] but also removed the requirement of a binder or any gelling agent that are widely used in ceramic DIW, as the product was sturdy enough to be handled and cleaned off the bottom support $[6,7,31]$. Figure 9 depicts three parallel processes that happen upon drying. First is the snapping of the support structure that compensates shrinkage (Figure 9 B Red). The second occurs due to the reduced contact area between the printing bed and supports (Figure 9 B Green), compared to the area of the whole sample. This allows some of the support to easily separate from the printing bed and accommodate the drying induced shrinkage without any cracks on the product. The third process is represented as leaning of the support, where the top part of the support is following the shrinking green body while its bottom part still attached to the printing bed (Figure 9 B Blue). The third process is typically observed around the outer side of the product and usually follows the second process as, due to stretch and deformation, the support becomes more susceptible to be separated from the printing bed.

\section{Conclusion}

The systematic investigation of the titania inks resulted in a comprehensive parameter collection for the inks to be utilised in DIW. Different ink compositions were rheologically tested and then applied to the DIW in order to link rheological behaviour with extrudability potential. As a result, 
it was discovered that inks that display a shear-thinning behaviour and high extent of deformation after the creep stage are the best candidates for the DIW process, based on the consecutive extrudability tests. Additionally, the results produced for the PEG-based inks indicated the presence of a dilatancy peak in a region of 2 to $7 \mathrm{~s}^{-1}$. This peak appeared due to the jamming phenomenon that happens in systems of spherical particles and long polymeric chains. The peak, however, was almost eliminated after the implementation of the surface lubricant (i.e., oleic acid). This lubricant reduced the friction between particles, which reduced their agglomeration at the above-mentioned shear rate region. Eliminating the peak resulted in a better flowing ink and therefore increased quality of the final product. Moreover, the test results indicated that the most printable ink formula for the DIW of titanium dioxide to be 1:0.8:0.1:0.1 $\mathrm{TiO}_{2}: \mathrm{H}_{2} \mathrm{O}:$ PEG:oleic acid ink, which after drying only contained carbon and hydrogen as impurities and also had high porosity of $71 \%$. It was also established that commonly used PVA was not suitable for DIW of titania inks as it resulted in inks to be extremely sensitive to loading, reducing the reliability and repeatability of these inks. Finally, this study also presented and demonstrated the utilisation of a novel titania grid support for DIW, which eliminates cracks and shape deformation induced by the shrinkage of 3D printed titania products, removing the requirement for any specific treatment of the printing bed.

\section{Acknowledgement}

This work is supported by Natural Science Foundation of China [51804172] and the Ningbo Science and Technology Innovation 2025 Key Project [2018B10029]. 


\section{References:}

[1] J. Sun, Z. Peng, W. Zhou, J.Y.H. Fuh, G.S. Hong, A. Chiu, A Review on 3D Printing for Customized Food Fabrication, Procedia Manufacturing, 1 (2015) 308-319. https://doi.org/10.1016/j.promfg.2015.09.057 [2] J.-Y. Lee, J. An, C.K. Chua, Fundamentals and applications of 3D printing for novel materials, Applied Materials Today, 7 (2017) 120-133. https://doi.org/10.1016/j.apmt.2017.02.004

[3] A. Laptev, A.P. Cysne Barbosa, N. Daudt, M. Bram, Review of the powder metallurgical production of net-shaped titanium implants, Key Engineering Materials, 704 (2016) 311-317.

https://doi.org/10.4028/www.scientific.net/KEM.704.311

[4] Z. Chen, Z. Li, J. Li, C. Liu, C. Lao, Y. Fu, C. Liu, Y. Li, P. Wang, Y. He, 3D printing of ceramics: A review, Journal of the European Ceramic Society, 39 (2019) 661-687.

https://doi.org/10.1016/j.jeurceramsoc.2018.11.013

[5] W.E. Frazier, Metal Additive Manufacturing: A Review, Journal of Materials Engineering and

Performance, 23 (2014) 1917-1928. https://doi.org/10.1007/s11665-014-0958-z

[6] E. Peng, D. Zhang, J. Ding, Ceramic Robocasting: Recent Achievements, Potential, and Future

Developments, Advanced Materials, 30 (2018) 1802404. https://doi.org/10.1002/adma.201802404

[7] C. Minas, D. Carnelli, E. Tervoort, A.R. Studart, 3D Printing of Emulsions and Foams into Hierarchical

Porous Ceramics, Advanced Materials, 28 (2016) 9993-9999. https://doi.org/10.1002/adma.201603390

[8] S. Tang, Z. Fan, H. Zhao, L. Yang, F. Liu, X. Liu, Layered extrusion forming-a simple and green method for additive manufacturing ceramic core, The International Journal of Advanced Manufacturing Technology, 96 (2018) 3809-3819. https://doi.org/10.1007/s00170-018-1712-8

[9] X. Wei, E. Peng, Y. Xie, J. Xue, J. Wang, J. Ding, Extrusion printing of a designed three-dimensional YBa2Cu307-x superconductor with milled precursor powder, Journal of Materials Chemistry C, 5 (2017) 3382-3389. https://doi.org/10.1039/C6TC05393A

[10] G. Zhang, H. Chen, H. Zhou, Additive manufacturing of green ceramic by selective laser gasifying of frozen slurry, Journal of the European Ceramic Society, 37 (2017) 2679-2684.

https://doi.org/10.1016/j.jeurceramsoc.2017.02.040

[11] D. Macri, D. Sofia, D. Barletta, MassimoPoletto, P. Lettieri, SELECTIVE LASER SINTERING OF TITANIA POWDER: EXPERIMENTS AND MODELLING, (2017).

[12] M. Dehurtevent, L. Robberecht, J.-C. Hornez, A. Thuault, E. Deveaux, P. Béhin, Stereolithography: A new method for processing dental ceramics by additive computer-aided manufacturing, Dental Materials, 33 (2017) 477-485. https://doi.org/10.1016/j.dental.2017.01.018

[13] M. Zhou, W. Liu, H. Wu, X. Song, Y. Chen, L. Cheng, F. He, S. Chen, S. Wu, Preparation of a defectfree alumina cutting tool via additive manufacturing based on stereolithography - Optimization of the drying and debinding processes, Ceramics International, 42 (2016) 11598-11602.

https://doi.org/10.1016/j.ceramint.2016.04.050

[14] T. Xiaoyong, L. Dichen, G.H. Juergen, Rapid prototyping of porcelain products by layer-wise slurry deposition (LSD) and direct laser sintering, Rapid Prototyping Journal, 18 (2012) 362-373.

https://doi.org/10.1108/13552541211250364

[15] X. Lv, F. Ye, L. Cheng, S. Fan, Y. Liu, Binder jetting of ceramics: Powders, binders, printing parameters, equipment, and post-treatment, Ceramics International, 45 (2019) 12609-12624. https://doi.org/10.1016/j.ceramint.2019.04.012

[16] A. Ortona, C. D'Angelo, S. Gianella, D. Gaia, Cellular ceramics produced by rapid prototyping and replication, Materials Letters, 80 (2012) 95-98. https://doi.org/10.1016/j.matlet.2012.04.050

[17] Y. Wang, C. Wen, P. Hodgson, Y. Li, Biocompatibility of TiO2nanotubes with different topographies, Journal of Biomedical Materials Research Part A, 102 (2014) 743-751.

https://doi.org/10.1002/jbm.a.34738 
[18] T. Chen, A. Sun, C. Chu, H. Wu, J. Wang, J. Wang, Z. Li, J. Guo, G. Xu, Rheological behavior of titania ink and mechanical properties of titania ceramic structures by 3D direct ink writing using high solid loading titania ceramic ink, Journal of Alloys and Compounds, 783 (2019) 321-328. https://doi.org/10.1016/j.jallcom.2018.12.334

[19] M.A. Torres Arango, D. Kwakye-Ackah, S. Agarwal, R.K. Gupta, K.A. Sierros, Environmentally Friendly Engineering and Three-Dimensional Printing of TiO2 Hierarchical Mesoporous Cellular Architectures, ACS Sustainable Chemistry \& Engineering, 5 (2017) 10421-10429.

https://doi.org/10.1021/acssuschemeng.7b02450

[20] A.H. Aleni, I.F. Ituarte, A. Mohite, L. St-Pierre, J. Partanen, Comparing stiffness of solid and scaffold nano-TiO 2 structures produced by material extrusion method, Ceramics International, 44 (2018) 22312239. https://doi.org/10.1016/j.ceramint.2017.10.181

[21] A. Dolganov, M.T. Bishop, M. Tomatis, G.Z. Chen, D. Hu, Environmental assessment of the near-netshape electrochemical metallisation process and the Kroll-electron beam melting process for titanium manufacture, Green Chemistry, 22 (2020) 1952-1967. https://doi.org/10.1039/C9GC04036F

[22] G.Z. Chen, D.J. Fray, T.W. Farthing, Direct electrochemical reduction of titanium dioxide to titanium in molten calcium chloride, Nature, 407 (2000) 361-364. https://doi.org/10.1038/35030069

[23] D. Hu, A. Dolganov, M. Ma, B. Bhattacharya, M.T. Bishop, G.Z. Chen, Development of the FrayFarthing-Chen Cambridge Process: Towards the Sustainable Production of Titanium and Its Alloys, JOM, 70 (2018) 129-137. https://doi.org/10.1007/s11837-017-2664-4

[24] C. Schwandt, D.T.L. Alexander, D.J. Fray, The electro-deoxidation of porous titanium dioxide precursors in molten calcium chloride under cathodic potential control, Electrochimica Acta, 54 (2009) 3819-3829. https://doi.org/10.1016/j.electacta.2009.02.006

[25] D.T.L. Alexander, C. Schwandt, D.J. Fray, The electro-deoxidation of dense titanium dioxide precursors in molten calcium chloride giving a new reaction pathway, Electrochimica Acta, 56 (2011) 3286-3295. https://doi.org/10.1016/j.electacta.2011.01.027

[26] H. Chen, Y. Zeng, W. Li, J. Peng, X. Jin, G.Z. Chen, A PRS model for accurate prediction of the optimal solid oxide cathode structure for the preparation of metals in molten chlorides, Electrochemistry Communications, 26 (2013) 33-36. https://doi.org/10.1016/j.elecom.2012.10.005

[27] G. Lütjering, J. C.Williams, Titanium, 2nd ed., Springer, Berlin Heidelberg New York, 2007.

[28] P. Bajpai, Emerging Technologies in Sizing. PIRA Technology Report, Smithers PIRA, the worldwide authority on the Packaging, Print and Paper supply chains. Elsevier, 2004. https://doi.org/10.1016/B9780-12-803408-8.00003-2

[29] J. Ge, Z. Tan, W. Li, H. Zhang, The rheological properties of shear thickening fluid reinforced with SiC nanowires, Results in Physics, 7 (2017) 3369-3372. https://doi.org/10.1016/j.rinp.2017.08.065

[30] R.S. Farr, J.R. Melrose, R.C. Ball, Kinetic theory of jamming in hard-sphere startup flows, 55 (1997)

7203-7211. https://doi.org/10.1103/physreve.55.7203

[31] R. Riedel, I.W. Chen, Ceramics Science and Technology, Volume 3: Synthesis and Processing, Wiley2011.

[32] X.P. Chi, S. Yang, J.R.G. Evans, Extrusion Pressure Generated in High Alumina Content Paste Extrusion, IEEE.

[33] D.A. Brosnan, G.C. Robinson, Introduction to Drying of Ceramics: With Laboratory Exercises, Wiley2003.

[34] R.W. Ford, Ceramics Drying, Elsevier Science2013.

[35] R.C. Bradt, R.E. Tressler, Deformation of Ceramic Materials, Springer US2012.

[36] L. Chen, X. Tang, P. Xie, J. Xu, Z. Chen, Z. Cai, P. He, H. Zhou, D. Zhang, T. Fan, 3D Printing of Artificial Leaf with Tunable Hierarchical Porosity for CO2 Photoreduction, Chemistry of Materials, 30 (2018) 799806. https://doi.org/10.1021/acs.chemmater.7b04313 


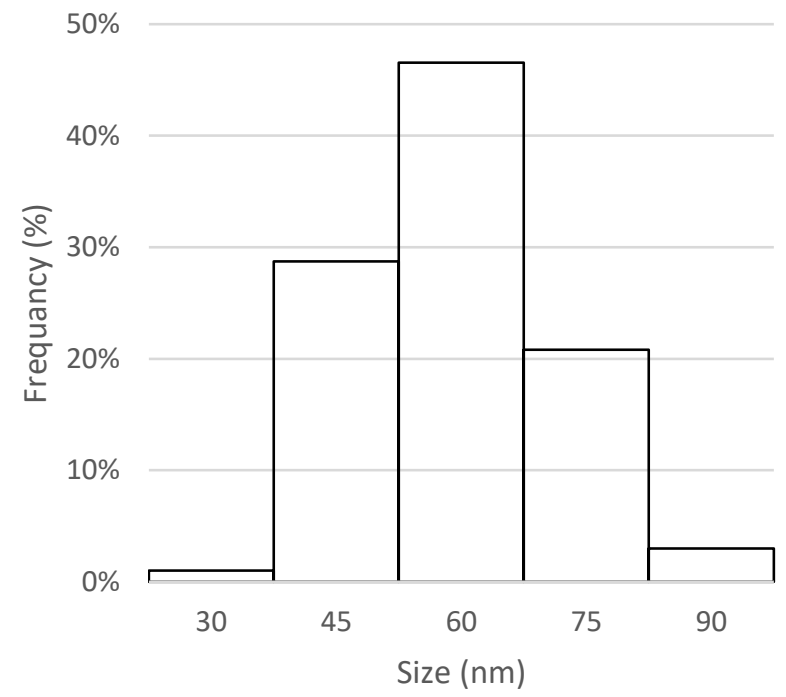

Figure 1: Particle size distribution of the used titania feedstock. 


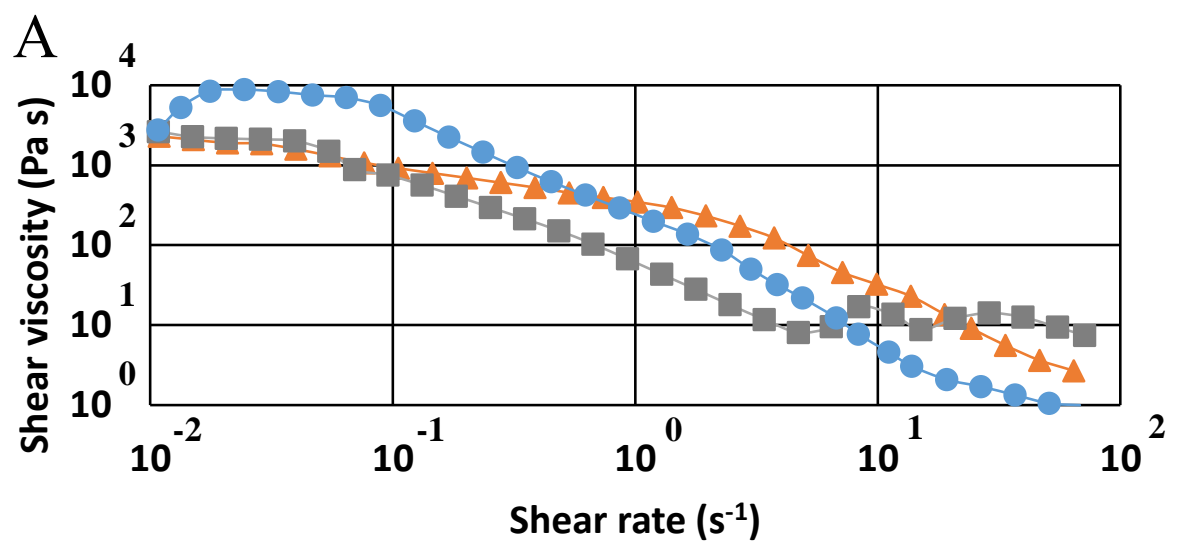

$-1: 0.8 \mathrm{H}_{2} \mathrm{O} \longrightarrow 1: 0.9 \mathrm{H}_{2} \mathrm{O}-1: 1 \mathrm{H}_{2} \mathrm{O}$

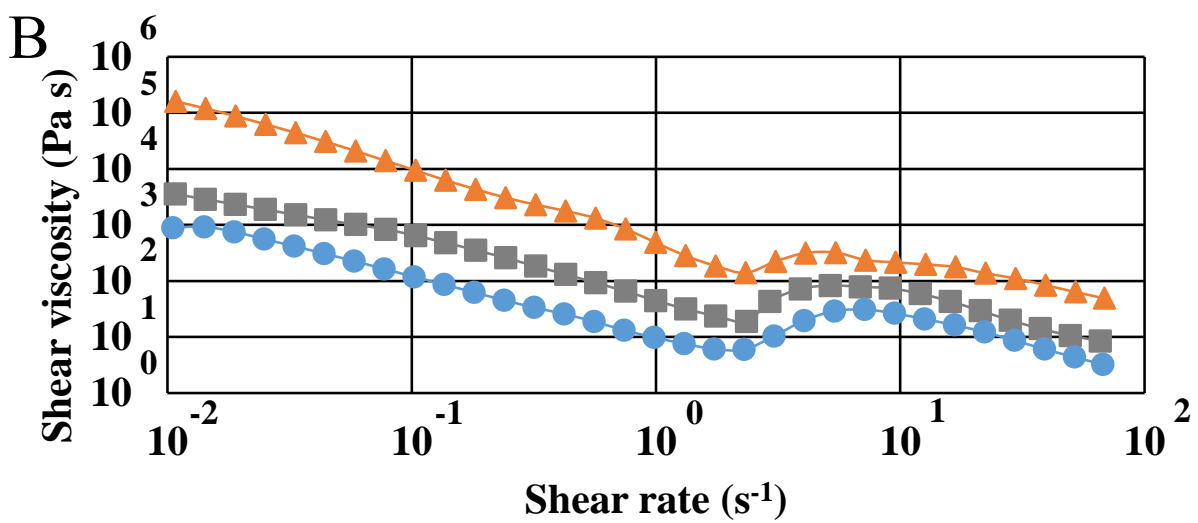

$\neg-1: 0.8: 0.1$ PEG -1:0.9:0.1 PEG - $-1: 1: 0.1$ PEG

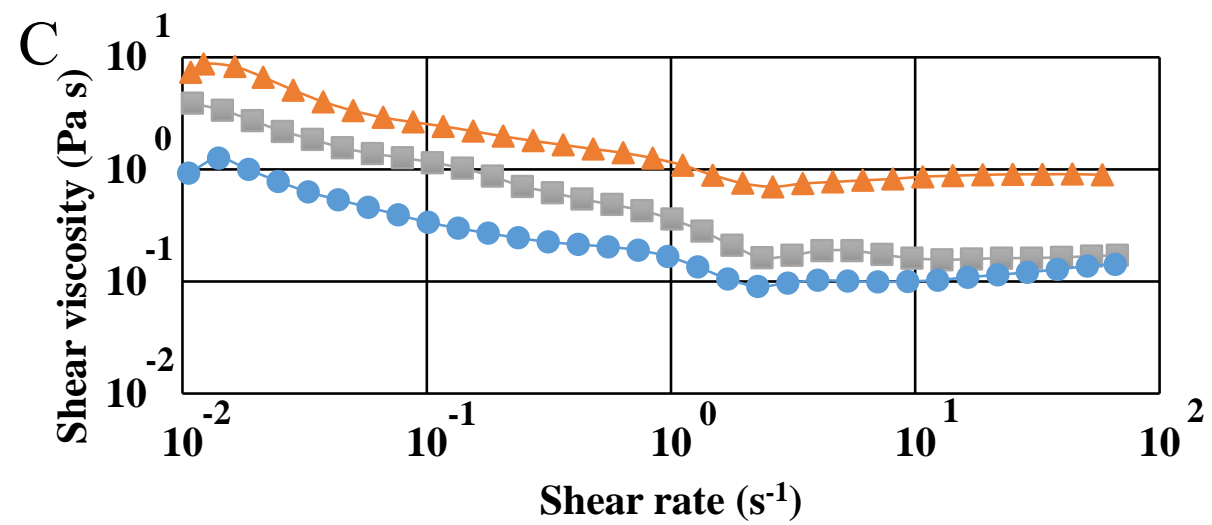

$\rightarrow-1: 0.8: 0.05$ PVA $\rightarrow$ 1:0.9:0.05 PVA $\rightarrow-1: 1: 0.05$ PVA

Figure 2: Shear rate vs viscosity tests on different weight ratios of $\mathrm{TiO}_{2}: \mathrm{H}_{2} \mathrm{O}:$ Rheological modifier (PEG or PVA). Awater based inks without any binders; $B$-inks with PEG as the binder; $C$-inks with PVA as the binder. 


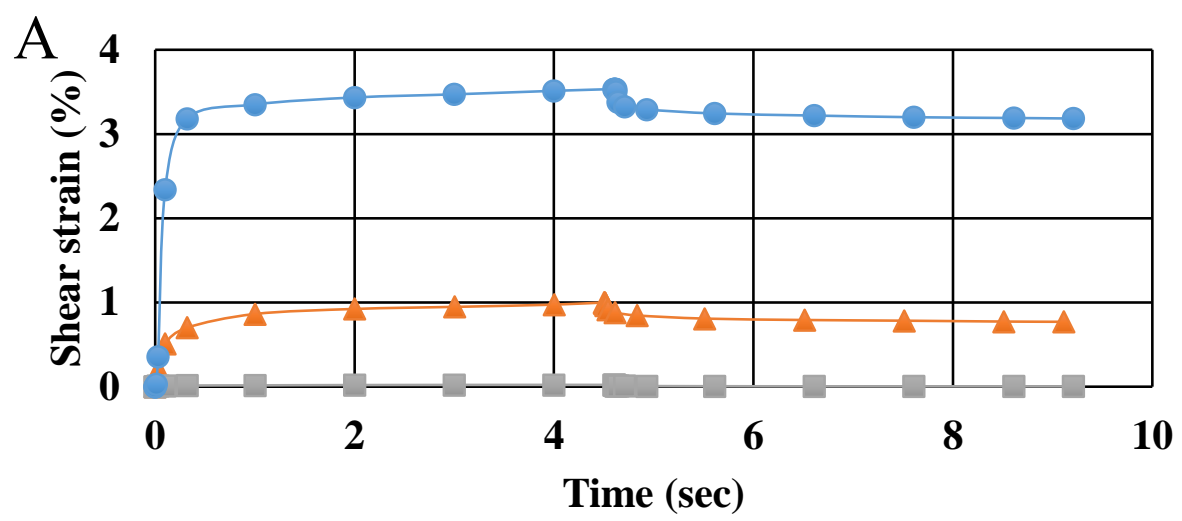

$-1: 0.8 \mathrm{H}_{2} \mathrm{O}-1: 0.9 \mathrm{H}_{2} \mathrm{O} \longrightarrow-1: 1 \mathrm{H}_{2} \mathrm{O}$

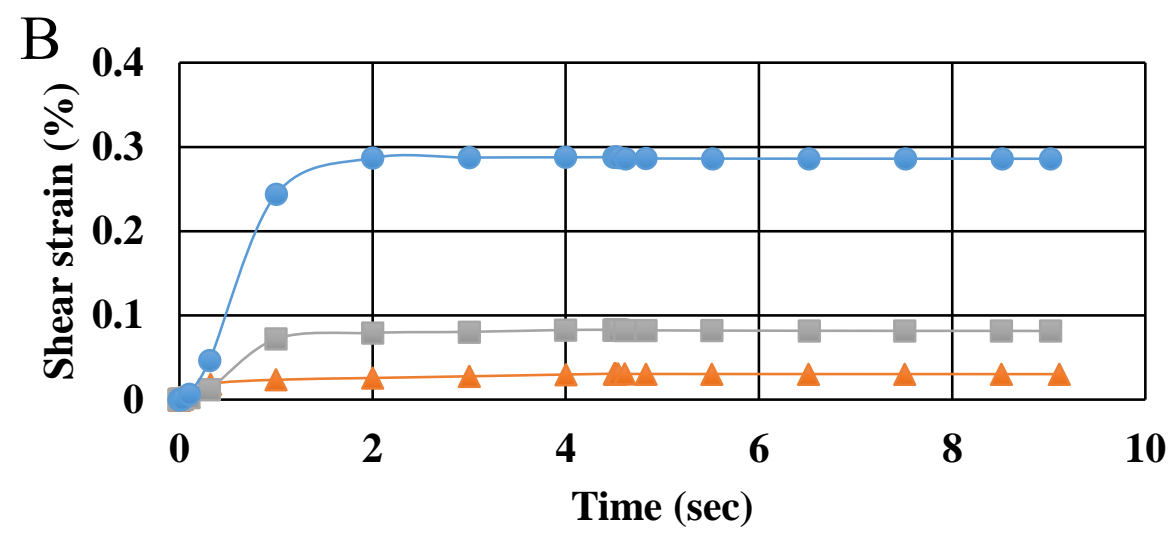

$\neg-1: 0.8: 0.1$ PEG $-1: 0.9: 0.1$ PEG $-1: 1: 0.1$ PEG

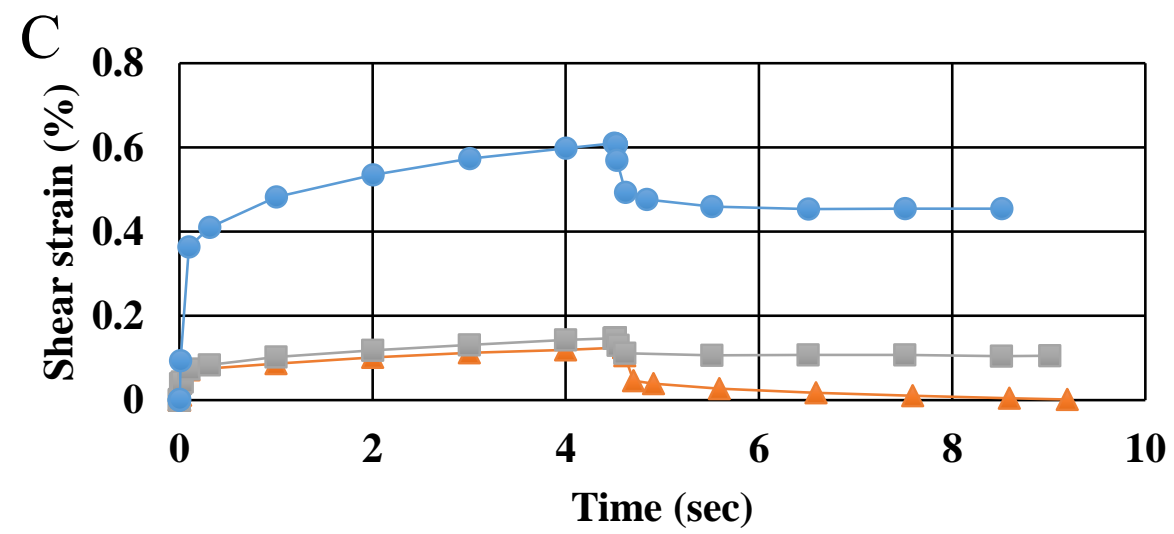

$$
-1: 0.8: 0.05 \text { PVA } \square \text { 1:0.9:0.05 PVA }-1: 1: 0.05 \text { PVA }
$$

Figure 3: Creep and recovery tests on different weight ratios of $\mathrm{TiO}_{2}: \mathrm{H}_{2} \mathrm{O}$ :Rheological modifier (PEG or PVA). Awater-based inks without any binders; $B$-inks with PEG as the binder; $C$-inks with PVA as the binder. 

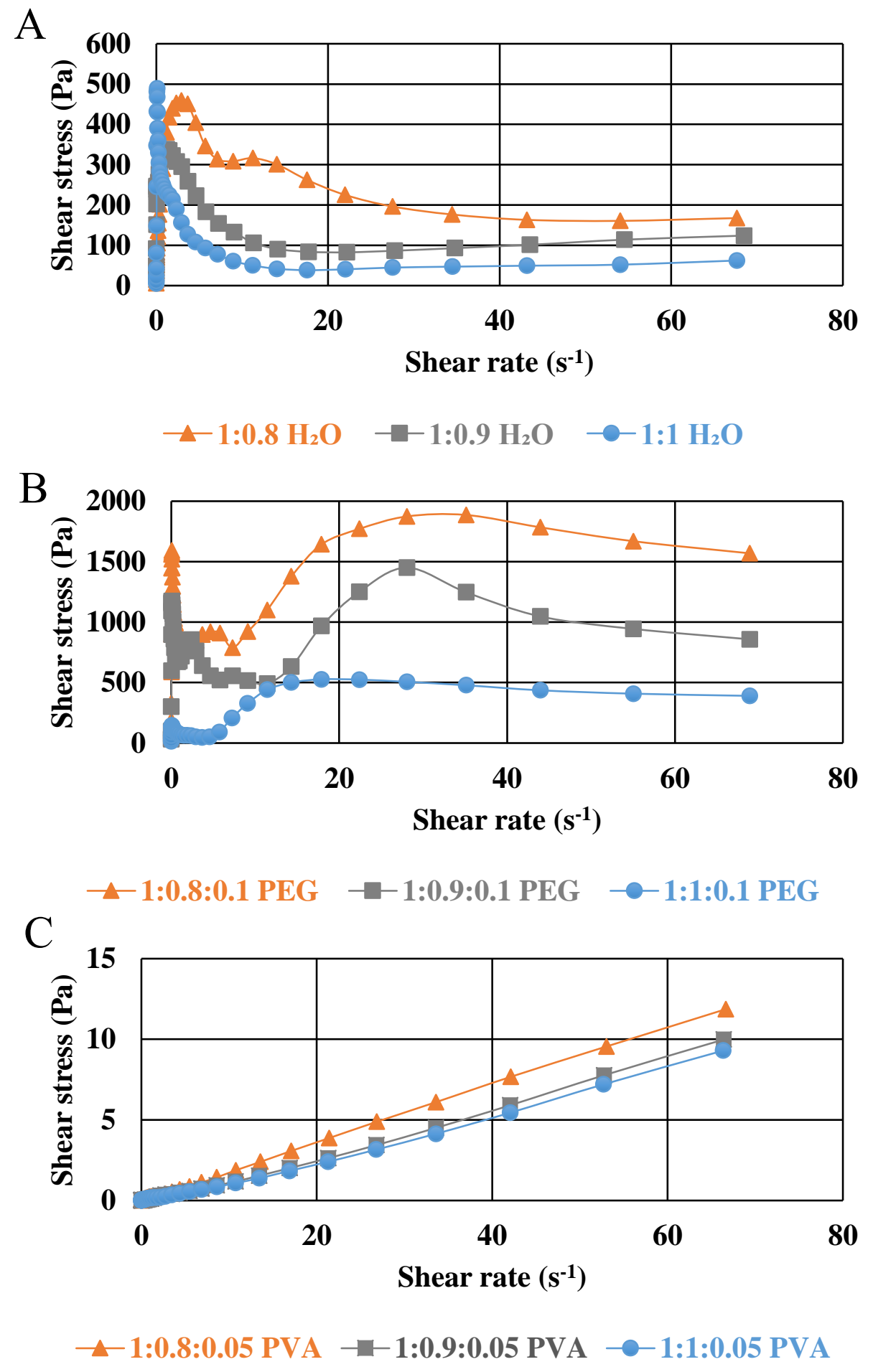

Figure 4: Shear rate vs shear stress plot acquired from different weight ratios of $\mathrm{TiO}_{2}: \mathrm{H}_{2} \mathrm{O}: \mathrm{Rheological}$ modifier (PEG or PVA). A-water-based inks; $B$-inks with PEG as the binder; $C$-inks with PVA as the binder. 


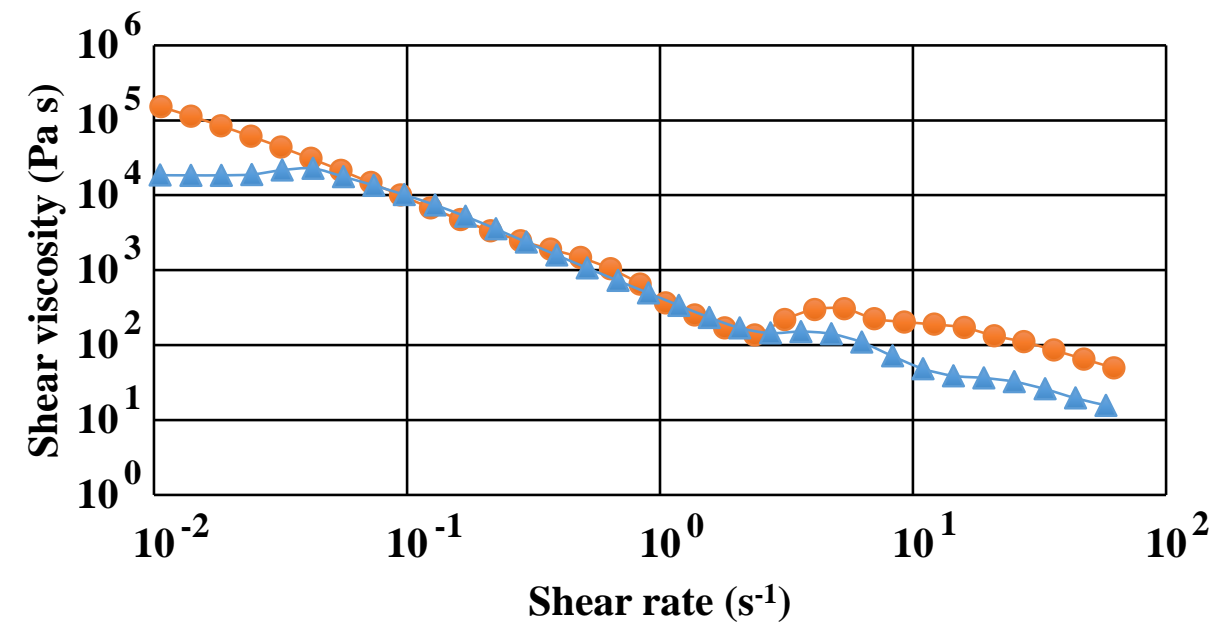

- Without oleic acid $-\leftarrow$ With 0.1 wt. ratio of oleic acid

Figure 5: Shear rate vs viscosity plots: comparison of the titania ink (1:0.8:0.1 $\left.\mathrm{TiO}_{2}: \mathrm{H}_{2} \mathrm{O}: \mathrm{PEG}\right)$ before and after the addition of the boundary lubricant (i.e., 0.1 wt. ratio of oleic acid). 


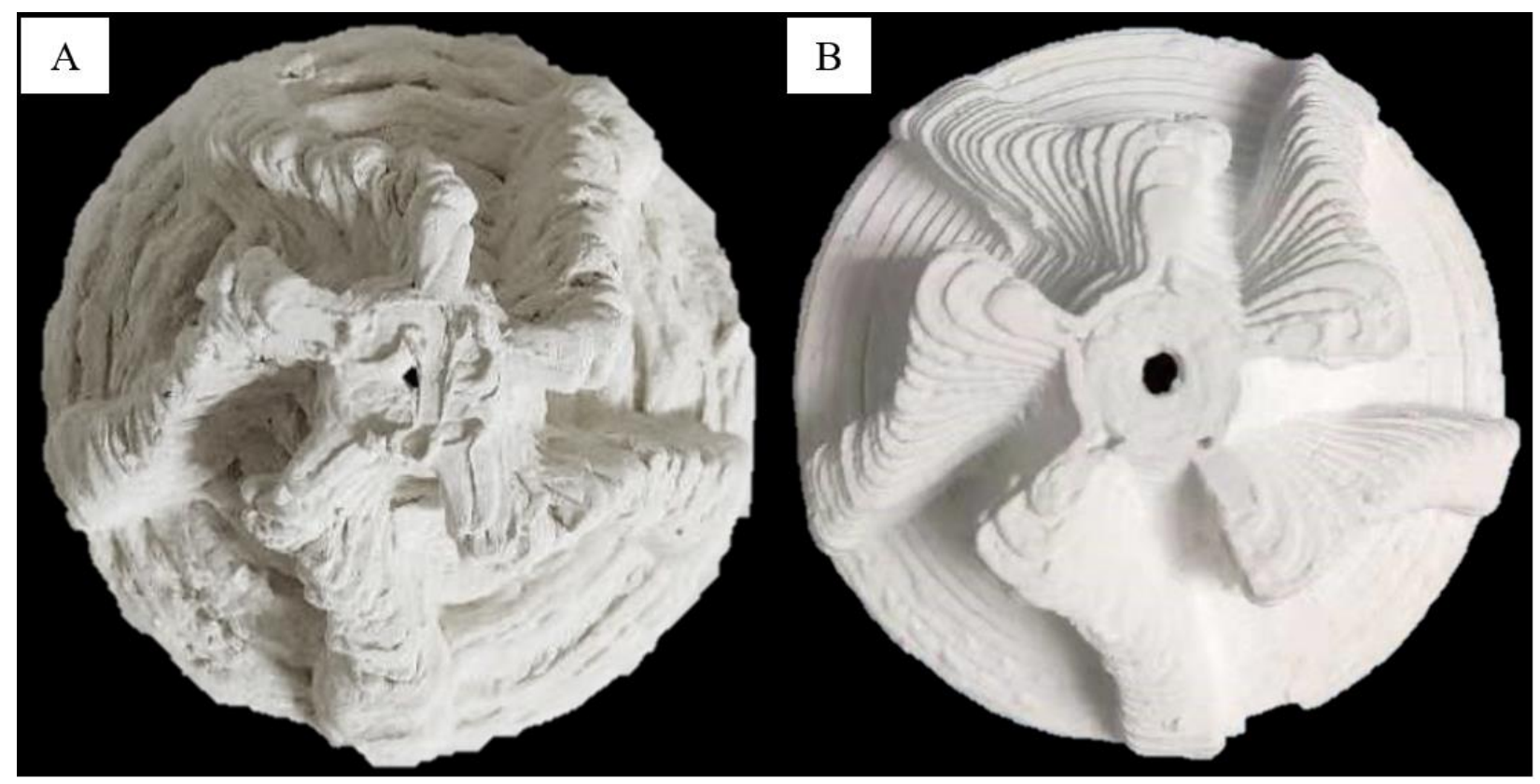

Figure 6: Impeller produced before $(A)$ and after $(B)$ adding the boundary lubricant (0.1 wt. ratio). 


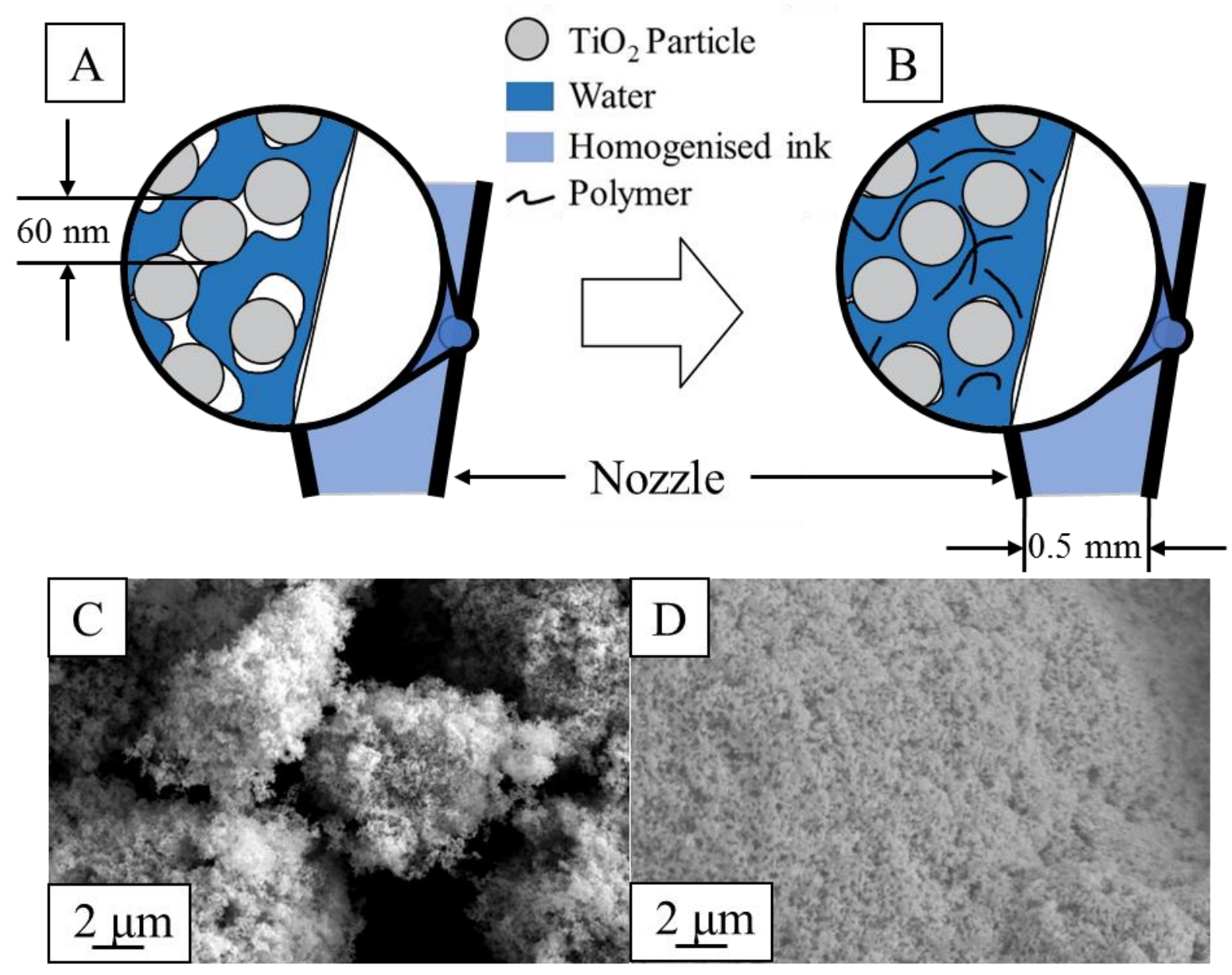

Figure 7: The effect of PEG onto the ink. A: The system schematics before the addition of PEG; B: The system schematics with PEG added; C: SEM image of the dried water-based ink; D: SEM image of the dried PEG-based ink. 


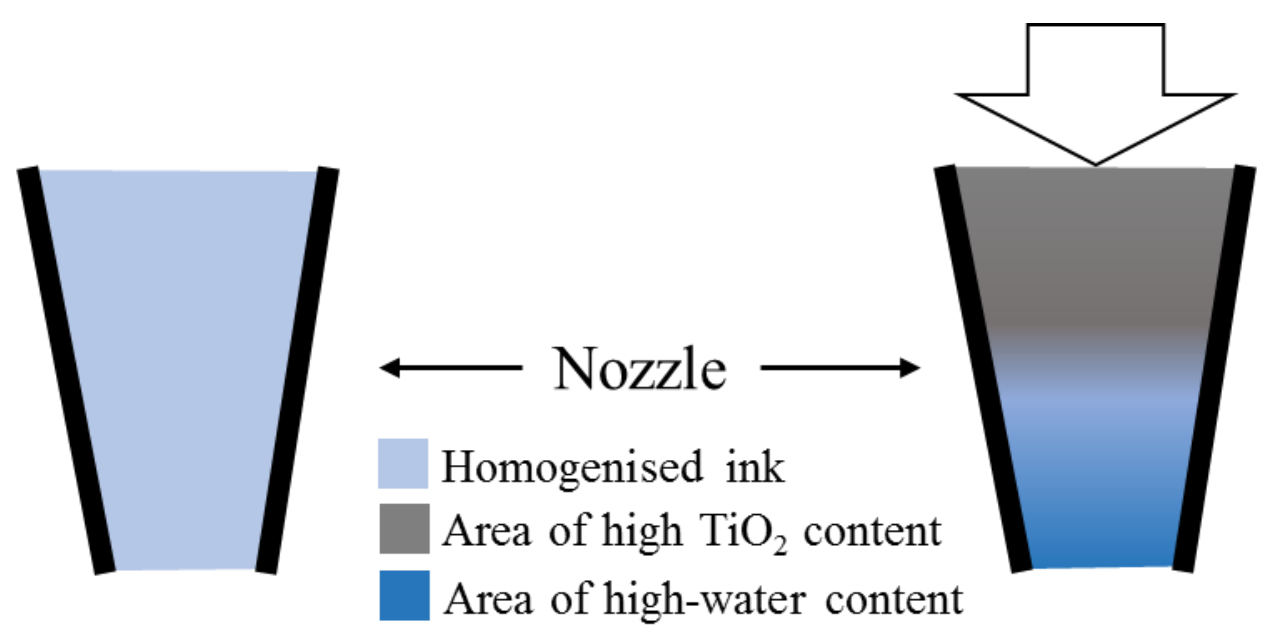

Figure 8: The migration of water under the applied pressure in the unstable ink. 

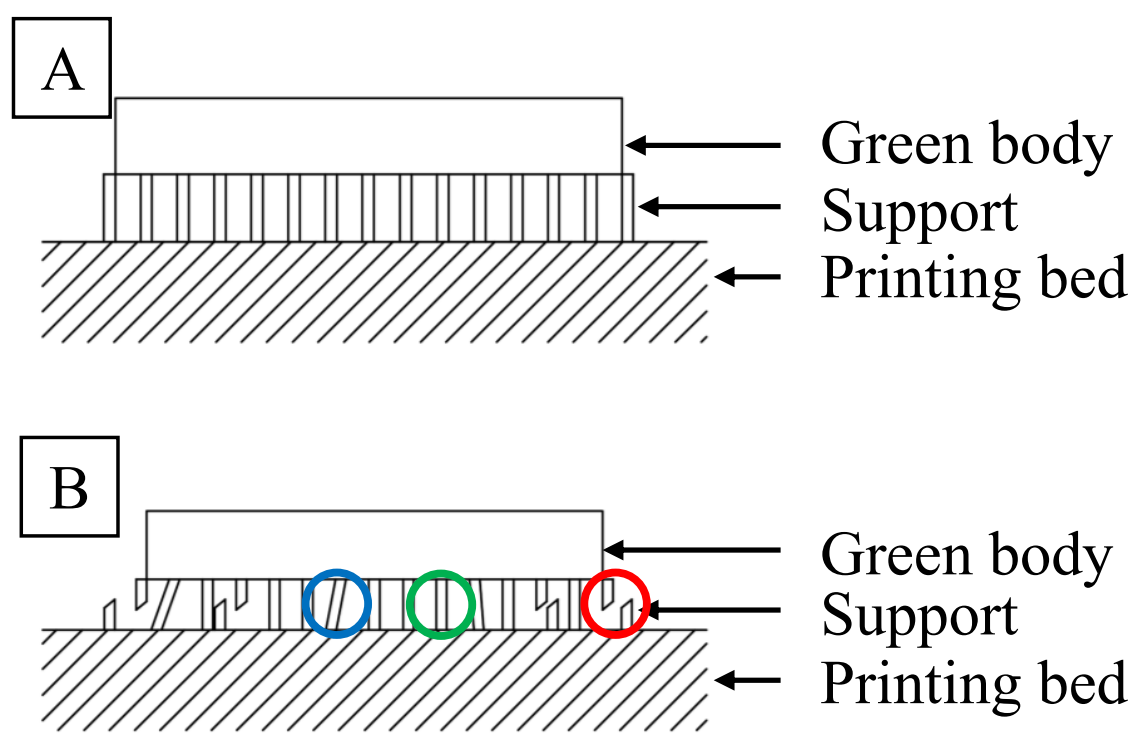

Figure 9: Drying-induced shrinkage on the support. A: After printing; B: After drying and shrinking. Red indicates snapping; Green - separation from bed; Blue - leaning. 
Table 1: Extrudability test results from a $0.5 \mathrm{~mm}$ nozzle.

\begin{tabular}{|c|c|c|c|}
\hline \multirow{10}{*}{$\begin{array}{c}\text { The 3D model } \\
\text { of the } \\
\text { investigated } \\
\text { rivet: }\end{array}$} & \multicolumn{3}{|c|}{ The weight ratio of $\mathrm{TiO}_{2}: \mathrm{H}_{2} \mathrm{O}$} \\
\hline & $1: 0.8$ & $1: 0.9$ & $1: 1$ \\
\hline & Unextrudable & Unextrudable & Unextrudable \\
\hline & \multicolumn{3}{|c|}{ The weight ratio of $\mathrm{TiO}_{2}: \mathrm{H}_{2} \mathrm{O}: \mathrm{PEG}$} \\
\hline & $1: 0.8: 0.1$ & 1:0.9:0.1 & $1: 1: 0.1$ \\
\hline & Controllably extrudable & Controllably extrudable & $\begin{array}{l}\text { Extrudable with } \\
\text { occasional } \\
\text { inconsistencies }\end{array}$ \\
\hline & & 1000000 & $10 \mathrm{mons}$ \\
\hline & \multicolumn{3}{|c|}{ The weight ratio of $\mathrm{TiO}_{2}: \mathrm{H}_{2} \mathrm{O}: \mathrm{PVA}$} \\
\hline & 1:0.8:0.05 & 1:0.9:0.05 & 1:1:0.05 \\
\hline & $\begin{array}{l}\text { Uncontrollably } \\
\text { extrudable }\end{array}$ & $\begin{array}{l}\text { Uncontrollably } \\
\text { extrudable }\end{array}$ & $\begin{array}{l}\text { Uncontrollably } \\
\text { extrudable }\end{array}$ \\
\hline
\end{tabular}

